\title{
Urbanização e produção da cidade: Shopping Centers na dinâmica de novas centralidades em Fortaleza-CE
}

\author{
José Borzacchiello da Silva* \\ Tiago Estevam Gonçalves**
}

\section{Resumo}

Presencia-se na cidade de Fortaleza, a partir da década de 1970, o processo de descentralização das atividades econômicas, diante disso, a estruturação da cidade passou a configurar-se por meio de vários núcleos de comércio e serviços. Dada à relevância da temática, nesse estudo haverá uma análise da cidade de Fortaleza, com o objetivo de entender a relação entre shopping centers e expansão urbana, a partir da formação de novas centralidades. Desse modo, com vista à concisão do texto, encontra-se sistematizado em três partes, na primeira abordar-se-á a temática centralidade e shopping centers; na segunda parte apresentar-se-á a cidade de Fortaleza e as imbricações da produção do espaço urbano e as novas centralidades. Por fim, na terceira sentença analisar-se-á o shopping na produção da cidade e a cidade na produção do shopping.

Palavras-chave: Atividades comerciais; Novas centralidades; Shopping centers.

City's production and urbanization: Shopping malls in the new centrality and dynamic in Fortaleza-CE

\begin{abstract}
Since the 1970s, a process of decentralization of economic activities has been observed in the city of Fortaleza, which has

\footnotetext{
* Professor Titular do Depto. de Geografia - Centro de Ciências - UFCE.

** Instituto Federal de Educação, Ciência e Tecnologia de Alagoas.
}

Geosul, Florianópolis, v. 27, n. 53, p 63-88, jan./jun. 2012 
SILVA, J.B. \& GOLÇALVES, T.E. Urbanização e produção da cidade: ...

resulted in the formation of a number of different commercial and service-based nuclei within the urban area. Given the importance of this theme, the present study analyzes this phenomenon with the aim of understanding the relationship between shopping malls and urban expansion, based on the formation of new nuclei. For the sake of conciseness, the text is divided into three sections. The first assesses the theme of centralization and shopping malls. The second section focuses on the city of Fortaleza and the overlap of the production of urban spaces and new centralities. Thirdly, the role of the mall in the production of the city and the city in the production of the mall will be analyzed.

Key words: Commercial activities, New centralization, Shopping malls.

\section{Introdução}

No movimento de "construção" e "desconstrução" do urbano, há a tentativa de desvendar a teia de relações justapostas e sobrepostas na articulação entre os shopping centers a nova configuração urbana de Fortaleza. Essas relações estão pautadas na discussão sobre as mudanças ocorridas na estruturação da cidade.

Entende-se ser necessário analisar as consequências de tais modificações, a partir da análise dos equipamentos modernos (shoppings) que aparecem com novos espaços de consumo ou novos consumos de espaço que criam e recriam novas formas para atrair as pessoas ao consumo.

Nesse sentido, as mudanças vigentes na sociedade urbana estão correlacionadas com a expansão e modernização das atividades terciárias, entre os vários tipos comerciais destacam-se os shopping centers, sendo que tais equipamentos tornaram-se grandes centros de convergência da urbes, agindo consideravelmente no modo de vida nas cidades, assim como, impulsionando o desenvolvimento e transformações urbanas. 
SILVA, J.B. \& GOLÇALVES, T.E. Urbanização e produção da cidade: ...

As cidades são fundamentalmente centros terciários. Isto porque elas empregam o maior número de pessoas no setor de comércio e de serviços, sejam as cidades "fillhas do comércio", sejam "lugares de mercados". A cidade é a materialização da ação dos vários agentes sociais. Assim, a cidade é o resultado da própria história espacializada da sociedade (Salgueiro, 1996).

Nesta perspectiva, em Fortaleza, a partir de diversos fatores de expansão surgem e desenvolvem-se novos espaços de atividades terciárias. Destaca-se que, em cada cidade temos características específicas de formação de novas centralidades e em épocas que também podem ser distintas. Nesse estudo haverá uma análise da cidade de Fortaleza, com o objetivo de entender a importância dos shopping centers na dinâmica de novas centralidades que se formaram pós-década de 1970.

A cidade, no seu conjunto, sofre com o acentuado processo de centralização e descentralização que é ao mesmo tempo combinado e contraditório. A cidade contemporânea se caracteriza pela capacidade de atração e de diferentes níveis de concentração. A concentração contrapõe-se ao fenômeno expressivo de descentralização, como se a cidade continuamente se espraiasse indefinidamente no sentido de sua periferia como forma de diluir para se recompor em novas formas de concentração. Pode-se até pensar no surgimento de cidades na cidade, contudo não quer dizer que a cidade não seja "una".

É a natureza dessa trama urbana distendida, de densidades múltiplas - que combina concentração com descentralização, localizações com fluxos, imóveis com acelerados e diversos ritmos de mobilidade no interior dos espaços urbanos - que redefine o par centro-periferia, a partir da constatação de que há várias centralidades em definição e diferentes periferias em constituição (SPOSITO, 2001, p.89).

Com relação a esta temática de concentração e desconcentração, centralização e descentralização, destacam-se 
SILVA, J.B. \& GOLÇALVES, T.E. Urbanização e produção da cidade: ...

alguns conceitos: estrutura urbana, estruturação urbana, centralidades. Desse modo, com vista à concisão do texto, encontra-se sistematizado em três partes, na primeira abordar-se-á a temática centralidade e shopping centers; na segunda parte apresentar-se-á a cidade de Fortaleza e as imbricações da produção do espaço urbano e as novas centralidades. Por fim, na terceira sentença analisar-se-á o shopping na produção da cidade e a cidade na produção do shopping.

\section{Abordagens teóricas: centralidades e shopping centers}

Conforme Sposito (1998), a centralidade urbana pode ser abordada em duas escalas territoriais: a intra-urbana e a rede urbana. No primeiro nível, enfoca as diferentes formas de expressão dessa centralidade, tomando como referência o território da cidade ou da aglomeração urbana, desde o centro ou centros. No segundo plano, a análise toma como referência a cidade ou aglomeração urbana principal em relação ao conjunto de cidades de uma rede. Esta, por sua vez, pode ser vista em diferentes escalas e formas de articulação e configuração, de maneira que se possa compreender o papel da cidade central.

Nessa análise, intenta-se deter ao primeiro nível de escala territorial apresentado por Sposito (1998), no qual averiguará as relações socioespaciais entre shopping center e a dinâmica intraurbana das novas centralidades. Contudo, não significa dizer que ao aprofundar-se nesse nível de discussão, não possa em alguns instantes apontar questões relevantes da dinâmica intermetropolitana, ou seja, do nível de rede urbana.

$\mathrm{Na}$ mesma perspectiva de Sposito (1998), Reis (2006) acentua que a dispersão urbana pode ser estudada no âmbito de duas escalas. A primeira diz respeito às áreas metropolitanas e a segunda ao tecido urbano. Quanto à segunda, ora é discutida, por meio das mudanças que ocorrem na organização do tecido urbano, tendo a participação de empreendimentos de grande porte, como os shopping centers. 
SILVA, J.B. \& GOLÇALVES, T.E. Urbanização e produção da cidade: ...

Nessa perspectiva tratar-se-á sobre a questão da centralidade, respeitante à constituição de lugares como pontos de acumulação e atração de fluxos, centro mental e social definido pela reunião e pelo encontro. É uma forma vazia que requer de relações sociais, objetos e situações (CARLOS, 2001).

A cidade apresenta-se fragmentada mediante a disposição desigual de fenômenos nas suas distintas parcelas, produzindo por sua vez, uma articulação de suas "partes" que tende a se configurar de forma distinta, atrelada à segmentação de áreas. Com efeito, pode-se destacar a ideia de que as "partes" da cidade, ou melhor, seus espaços, se apresentam com maior ou menor poder de articulação. Consequentemente, os espaços com maior poder de articulação tendem a atrair para si pressupostos de concentração de determinados fixos e, em seguida, fluxos de pessoas, capitais e mercadorias. Com isso são capazes de constituir uma centralidade.

Com o avanço de mudanças estruturais da cidade, onde apresenta-se cada vez mais polinucleada. Whitacker (2003, p.61) nos diz que "a cidade é cristalização da urbanização e essa, enquanto processo, não é definida, in fine, mas se articula à produção ampla e restrita".

Nesse sentido, no âmbito da produção do urbano, pode-se apontar o fenômeno shopping center, no qual vem crescendo de importância a nível, mundial, nacional, local. Este tipo de empreendimento tem seduzido amplos setores e atores sociais.

Nesta parte do trabalho tentar-se-á realizar algumas definições e análises quanto ao seu avanço dos shopping centers no urbano. Esses equipamentos surgem a partir das necessidades de adaptação do comércio varejista às mudanças macro-econômicas da sociedade capitalista, tendo em vista a urbanização acelerada, o papel do capital financeiro no urbano, compra e o acesso ao automóvel.

O surgimento e proliferação de equipamento terciário é uma das formas de objetivação de ambiente construído destinado à comercialização e ao consumo de mercadorias, transcorreu no bojo da concentração do capital. À progressiva mudança das formas de organização, métodos e técnicas de produzir, correspondeu a 
SILVA, J.B. \& GOLÇALVES, T.E. Urbanização e produção da cidade: ...

incorporação encadeada de inovações nos modos de troca (BIENENSTEIN, 2001).

O shopping center é entendido como um fenômeno moderno da sociedade capitalista, que tem tido repercussões na forma de viver da sociedade urbana. Sendo que, o cotidiano é perpassado, cada vez mais, pela a artificialidade destes espaços privados.

Nesse contexto, os shopping centers surgiram nos Estados Unidos pós-segunda guerra mundial e estão relacionados com o nascimento e expansão dos subúrbios e com o advento do automóvel. Com relação ao processo de formação dos equipamentos modernos temos diferenças na escala espaçotemporal dos shoppings estadunidenses e brasileiros, além disso, temos diferenças de nomenclaturas, destacamos que nos Estados Unidos e Canadá os shopping centers são designados de shopping mall, enquanto no Brasil temos a utilização do termo shopping Center [2] (PADILHA, 2006).

Rybczynski (1996) destaca que provavelmente o primeiro shopping center foi o Northgate, inaugurado em $1^{\circ}$ de maio de 1950, nos arredores da cidade de Seatle. Este empreendimento foi projetado pelo o arquiteto John Graham Jr. No Brasil, em 27 de novembro de 1966, deu-se a inauguração do primeiro shopping no país, o shopping center Iguatemi, marcou deste modo, uma nova forma de organização comercial. Ao analisar esse surgimento, sua evolução e as variadas formas, esses equipamentos revelam-se como um novo sistema de comercialização moderno que alterou/ra a "ordem" urbana.

No que tange a definição de shopping a Abrasce diz que: é um centro comercial planejado, sob administração única e centralizado, composto de lojas para locação com estacionamento próprio suficiente para atender as necessidades do empreendimento. Os shopping centers apresentam algumas características específicas: projeto arquitetônico, localização num único terreno de fácil acesso, área de estacionamento, áreas de acesso de entrega de mercadorias, ter um grupo de inquilinos que 
SILVA, J.B. \& GOLÇALVES, T.E. Urbanização e produção da cidade: ...

proporcione variedades de mercadorias, um ambiente com conforto, segurança.

Shopping center significa: um empreendimento imobiliário de iniciativa privada que reúne, em um ou mais edifícios contíguos, lojas alugadas comércio varejista ou serviços. O tenant mix planejado pela empresa prevê a presença de várias lojas do mesmo ramo distinto, como também por sua natureza distinta (lojas âncoras e lojas de comércio especializado e serviços - que podem ou não pertencer a redes) (PINTAUDI, 1992).

É importante ressaltar que, os shoppings incorporaram uma gama de serviços e atividades, e que essa tendência tem sido muito bem articulada aos interesses do capital, ampliando possibilidades/oportunidades de acumulação.

Lefebvre (1993) observa que, em qualquer época, as sociedades produziram seu espaço; mas, na sociedade capitalista, "as forças produtivas acarretam, não somente a produção das coisas, mas também daquilo que as contêm, a saber, o espaço". Noutras palavras, o capital, que outrora se limitava à produção de mercadorias móveis, a partir do século XIX, passou a investir na produção do espaço construído, o que determina implicações espaciais do modo de produção capitalista.

Em um processo de progressiva presença deste espaço construído e "novo" na realidade urbana representam uma grande força de concentração de atividades terciárias num único local. Pode-se pensar que os shoppings, representam parte de um processo de "inovação" da cidade no capitalismo monopolista, como uma forma inédita na realidade urbana, em princípio. De fato, a concentração de equipamentos, atividades comerciais e de serviços é necessária para ensejar uma dinâmica nos fluxos, sobretudo de mercadorias. Esta concentração, ao propiciar uma centralização urbana, produz uma diferenciação do solo e no seu uso.

Castells (2000) destacou a centralidade urbana como elementochave das articulações entre os demais componentes da estrutura urbana. A centralidade apresenta-se como local geográfico e conteúdo social. Então pode ser vista como local de convergência, de reunião, 
SILVA, J.B. \& GOLÇALVES, T.E. Urbanização e produção da cidade: ...

encontro, dotado de determinado conteúdo social, sem deixar de ter as materializações de suas formas.

\section{Novos entendimentos sobre as centralidades em Fortaleza}

A morfologia urbana ${ }^{1}$ de Fortaleza passa por significativas mudanças, esse processo ${ }^{2}$ se torna mais evidente a partir da década de 1980, 1990, contudo observar-se precedentes significativos na década de 1970.

Compreende-se morfologia urbana como um conceito amplo e representativo no processo de estruturação urbana da cidade em que permeia relações espaço - temporais, pois o tempo atual impresso na forma da cidade dialoga com os tempos inerentes a formas existentes nos hábitos da sociedade, tais temporalidades dizem respeito a uma história humana como realização da vida no espaço e através dele, produzindo assim, espacialidades (CARLOS, 2001).

Então, Fortaleza caracterizar-se-á a partir da década de 1970 pela expansão do seu tecido urbano de forma intensa, mas descontínua, seus espaços se redefinem. Ao invés de aglomerações urbanas que designam contigüidade e adensamento populacional, de infra-estrutura e equipamentos, produzem-se largas tramas urbanas que se definem por uma estruturação polinucleada ${ }^{3}$, ou seja, formação de novas áreas comerciais, na qual esta dinâmica está articulada há uma série de fatores.

${ }^{1}$ A morfologia refere-se ao espaço construído e reflete a organização econômica, social e política, sendo assim um conceito inerente ao da estrutura urbana. Em se tratando de morfologia urbana, é salutar destacar que o conceito de morfologia abarca muito mais do que é compreendido em relação ao termo morfologia, no qual ultrapassa a forma e vai além da extensão urbana (CAPEL, 2002; SPOSITO, 2004).

2 Utilizamos o conceito de processo porque é mais adequado metodologicamente para o estudo de mudanças e permite a compreensão delas como resultado de conjuntos de relações.

${ }^{3}$ A idéia de policentralidade da cidade atual com diversas expressões de centralidades se fundamenta nas formulações de Lefebve (2002). 
SILVA, J.B. \& GOLÇALVES, T.E. Urbanização e produção da cidade: ...

Essa nova morfologia está marcada por um padrão de desconcentração territorial que não pode ser compreendido com negação de aglomeração, mas com condição e expressão de novas lógicas de localização, que engendram novas práticas sociais e que realizam redesenhando essa nova morfologia (SPOSITO, 2001, p.85).

Sobre a análise de desconcentração territorial de Fortaleza, Silva (2008) nos traz contribuições para o entendimento. Ao discutir a respeito da fragmentação de Fortaleza.

A fragmentação é um conceito que se refere à complexa divisão do trabalho no interior da metrópole, quando ela se reestrutura e se refuncionaliza. Aplica-se nos casos da polinucleação, principalmente quando os principais serviços e atividades migram do centro tradicional e se instalam noutros setores da cidade, dando origem a subcentros, sendo que alguns superam em movimento o centro antigo tradicional. Em cidade muito dinâmica, essa migração ocorre algumas vezes, sendo constante a eleição temporária de certos setores como o subcentro mais importante. A fragmentação ocorre quando a centralidade - o centro tradicional, a cidade monocêntrica não dá mais conta de atender a todas as demandas urbanas (SILVA, 2008, p. 151-152).

Com isso, a cidade apresenta-se com parcelas do tecido urbano que dispõem de maior concentração de atividades, dessa forma modela e gera articulação entre os espaços. Por conseguinte, esses espaços geram atração sobre as demais parcelas do tecido urbano e constitui assim as centralidades (OLIVEIRA JÚNIOR, 2008).

No que tange à localização espacialmente, de forma concentrada, o Centro tradicional de Fortaleza, até recentemente, era a única centralidade urbana, mas com a fragmentação, áreas residências e o setor terciário se descentralizaram pelo tecido urbano, como consequência se formaram novas centralidades.

A criação de "novas centralidades" contribuindo para lançar as bases de uma estrutura policêntrica de territórios ligados em rede à custa da perda da importância do centro 
SILVA, J.B. \& GOLÇALVES, T.E. Urbanização e produção da cidade: ...

tradicional e da estrutura monocêntrica de base hierárquica, ao mesmo tempo em que favorece a proliferação de implantações do tipo pontual (centros comerciais, condomínios de luxo, grandes edifícios de escritórios, conjuntos de habitação social, parques temáticos) (SALGUEIRO, 1998, p.42).

Presencia-se na cidade de Fortaleza, o processo de descentralização das atividades econômicas. Assim ocorre o surgimento de novas centralidades na cidade, como por exemplo, nos bairros do Montese e da Aldeota.

$\mathrm{Na}$ Avenida Gomes de Matos, no bairro do Montese se desenvolve lojas de autopeças, além disso, se estabelece como um pólo de confecções. O comércio tem como característica a facilidade de acesso, ocasionada pela proximidade de "pontoschave" de escoamento, como a Rodoviária, o Aeroporto e como elo do Distrito Industrial de Maracanaú.

No Montese, ao longo da Avenida Gomes de Matos, em virtude do papel de conexão regional rodoviária, da proximidade de Parangaba e do predomínio de uma população de baixo nível de renda, desenvolve-se pequeno comércio local e de autopeças, posteriormente atraindo a instalação de filiais de lojas do centro e agências bancárias (COSTA, 2005, p.82).

A localização do Montese facilitou o escoamento das mercadorias comerciais para outros bairros e cidades. Esse bairro aos poucos se concretizou como uma nova centralidade na cidade. Apresenta como importantes avenidas: Alberto Magno e Gomes de Matos. E os bairros de destaque que compõem essa centralidade são: Damas, Vila União, Bom Futuro, Parreão e Jardim América.

Nesse mesmo período, no bairro da Aldeota observa-se o surgimento de uma nova área comercial. Esta formação fora incentivada a partir da instalação do shopping - Center Um (1974) e mediante a presença de outras atividades comerciais. As principais avenidas dessa centralidade são: Santos Dumont, Barão 
SILVA, J.B. \& GOLÇALVES, T.E. Urbanização e produção da cidade: ...

de Studart, Dom Luis, Desembargador Moreira. Os bairros que fazem parte dessa centralidade são: Meireles, Dionísio Torres, Papicú e Varjota.

Além do Montese e da Aldeota, observar-se o aparecimento de outras centralidades como: a centralidade de Messejana, localizada ao sudeste de Fortaleza, exerce uma importante função econômica de núcleo comercial, de serviços e industrial. Os equipamentos nesta centralidade são os hospitais: Gonzaguinha, Hospital de Messejana e o Hospital Distrital Edmilson Barros de Oliveira - (Frotinha).

A centralidade da Parangaba liga os bairros do leste com o do oeste, do norte e sul. Apresentam-se alguns equipamentos importantes como: hospitais, terminais de ônibus e colégios. Além da Parangaba os principais bairros que compõem essa centralidade são: Maraponga, Itaperi, Vila Peri, Jóquei Clube e Bom Sucesso. Nessa centralidade os principais eixos viários são as avenidas: João Pessoa, Osório de Paiva, Godofredo Maciel e Dedé Brasil.

No bairro do Benfica, localizado aos arredores do Centro tradicional, sofre interferências desse em sua formação como centralidade, contudo aos poucos se consolida não apenas como um bairro de extensão do Centro tradicional, mas como uma centralidade que possui uma diversidade comercial e de serviços, destaca-se nesse quadro o Shopping Center - Benfica e a Universidade Federal do Ceará.

$\mathrm{Na}$ zona oeste destaca-se a centralidade da Barra do Ceará, localizada a noroeste do Centro, compreende Barra do Ceará, Álvaro Weyne, Carlito Pamplona, Cristo Redentor e Vila Velha. Sendo as principais avenidas: Presidente Humberto Castelo Branco (leste-oeste) e Avenida Francisco Sá, consolidou-se um núcleo comercial de serviços e industrial (LOPES, 2006). Essa centralidade sofre influências da centralidade do São Gerardo/Alagadiço, já que esta apresenta um grande número de comércio e serviços, além da presença do North Shopping.

A centralidade São Gerardo/Alagadiço, além da Avenida Bezerra de Menezes, tem como importantes eixos viários: Parsifal 
SILVA, J.B. \& GOLÇALVES, T.E. Urbanização e produção da cidade: ...

Barroso e Humberto Monte. A Centralidade do São Gerardo/Alagadiço influência também outros bairros como: Presidente Kennedy, Farias Brito, Parquelândia, Monte Castelo, Bela Vista e Rodolfo Teófilo.

A centralidade do Antônio Bezerra tem como bairros de influência: Quintino Cunha e Padre Andrade. A principal Avenida é a Mister Hull. Possui grande importância na zona oeste da cidade, já que possui um terminal de integração do Antônio Bezerra.

A centralidade do Edson Queiroz possui importantes equipamentos como Universidade de Fortaleza (UNIFOR), Fórum Clóvis Beviláqua e o Shopping Iguatemi. As principais avenidas: Washington Soares e Oliveira Paiva.

Diante dessa estruturação urbana, Fortaleza que tinha uma configuração de forma concentrada no Centro tradicional, que até recentemente era a única centralidade da cidade, passou por significativas modificações com o processo de fragmentação, o setor terciário passou a se descentralizar pelo tecido urbano, resultou assim, na formação de novas centralidades. Fortaleza passou a ser policêntrica "a policentralidade, tendência que se orienta seja para a constituição de centros diferentes (ainda que análogos, eventualmente complementares), seja para a dispersão e para a segregação" (LEFEBVRE, 2002, p.113).

A estruturação urbana de Fortaleza baseada em vários núcleos de comércio e serviços gerou uma complexidade de análise, com isso "cada fração da cidade deve ser analisada em suas especificidades, mas, ao mesmo tempo compreendida em suas relações com outras frações do mesmo espaço urbano e desses com outros espaços, relações estas estabelecidas por diferentes atores sociais" (SPOSITO, 2001, p.88). 
SILVA, J.B. \& GOLÇALVES, T.E. Urbanização e produção da cidade: ...

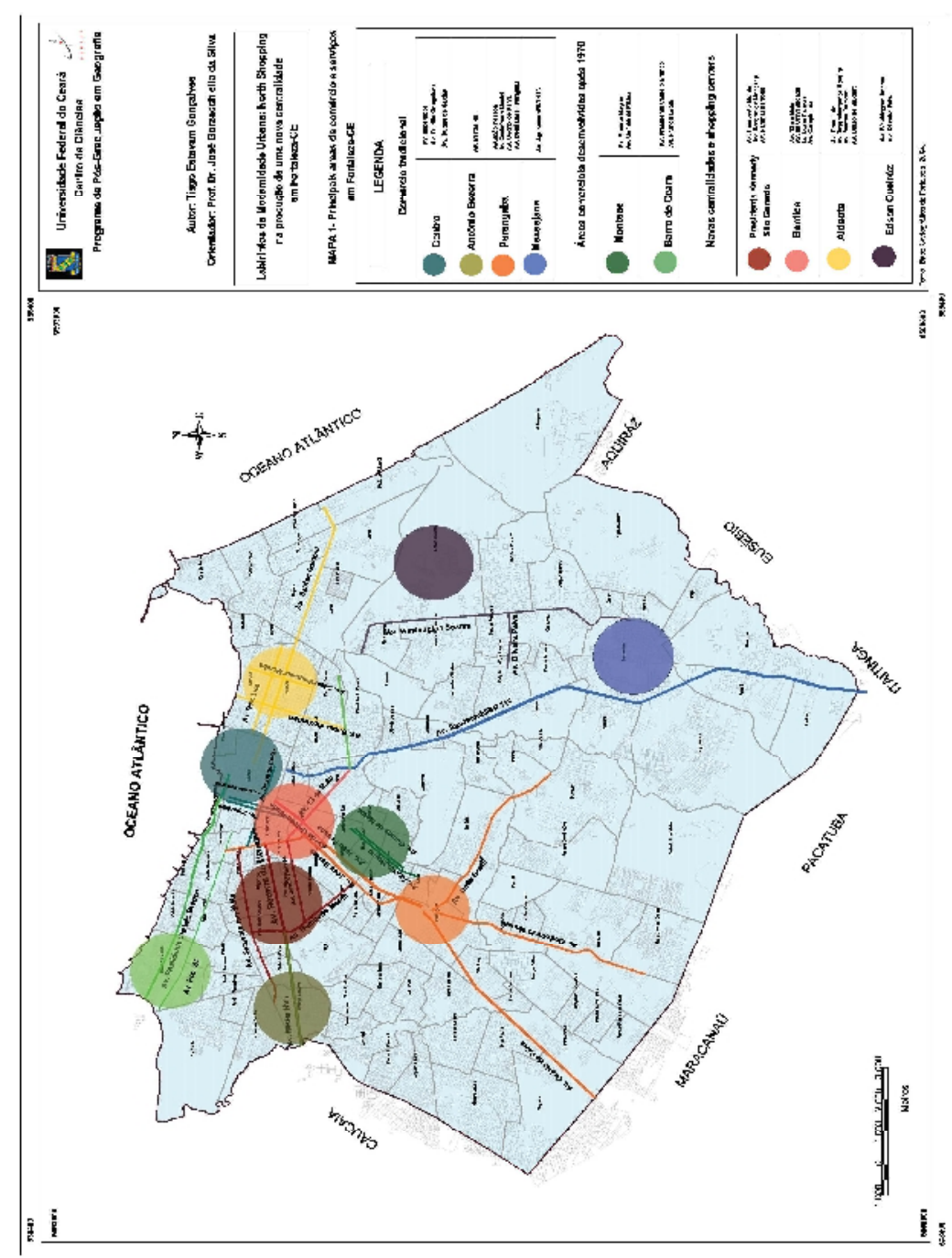

Fonte: Gonçalves, T.E. Labirintos da Modernidade Urbana: North Shopping na Produção de Novas Centralidades, Dissertação de Mestrado, UFC, 2009. 
SILVA, J.B. \& GOLÇALVES, T.E. Urbanização e produção da cidade: ...

A relação intrínsecas das novas centralidades e os shopping centers na cidade de Fortaleza, representam a concretização de novos processos estruturais no espaço urbano, assim incentivam novos vetores de valorização e expansão urbana, fundamentalmente, na área no entorno dos shopping centers, averiguou-se um incremento de novos fluxos e de novas atividades de comércio e serviços, permitindo assim, o fortalecimento de um caráter diferencial de determinadas parcelas da cidade.

Como afirma Sposito (1991) na medida em que comercializam diversos tipos de mercadorias e oferecem uma variedade de serviços, estes estabelecimentos criam novas centralidades, talvez com uma multiplicidade funcional, menor que a do centro tradicional. Além disto, a partir de sua instalação são atraídas outras atividades comerciais e de serviços para suas adjacências.

\section{Shopping centers como expressões na dinâmica de novas centralidades em Fortaleza}

O primeiro shopping da cidade foi o Center Um, em 1974, no bairro da Aldeota. Nesse bairro foi constituída uma nova centralidade, que se originou pela migração das classes mais abastadas, assim como pelos novos fluxos comerciais, tendo com empreendimento de inovação no espaço urbano fortalezense a implantação do Shopping Center Um. O Center Um foi inaugurado com um total de 45 lojas, supermercado Pão-de-Açúcar - Jumbo (loja âncora), cinema com 430 lugares, agências bancárias, estacionamento para 450 carros, lanchonetes, banca de revistas e jornais. "[...] Com a consolidação de uma infra-estrutura de comércio e serviços nos bairros chamados nobres, principalmente através da constituição de centros de compra acessíveis aos possuidores de carro (os shoppings são a expressão maior desses centros)" (DANTAS, 1995, p. 86). 
SILVA, J.B. \& GOLÇALVES, T.E. Urbanização e produção da cidade: ...

O Center Um, com um investimento maciço em publicidade, no qual estabelecia contrapontos com o Centro tradicional ${ }^{4}$ apresenta-se com idéias ligadas à modernidade ${ }^{5}$, enquanto com argumentos de poluição, estacionamento, violência ligadas ao Centro tradicional. Dessa forma, o Center Um consegue o seu intuito que era de atrair a população fortalezense, principalmente àquela residente na zona leste; torna-se assim um marco na cidade de Fortaleza tanto no que diz respeito a um novo locus de consumo e lazer como na estruturação urbana.

Depois que acabaram

Com a Coluna da Hora

Depois que derrubaram

O abrigo central

O centro da cidade

Mudou pra outro local

Lá tem ar para respirar

Tem coisas lindas para olhar

Tem muita coisa para comprar

Pois, o centro agora é Center Um

Em off: Center Um, o center da cidade

(O POVO, 1974).

No que tange ao crescimento do número de shoppings em nossa cidade, depois do Center Um (1974), teremos na década de

${ }^{4} \mathrm{O}$ centro urbano visto tradicionalmente como um espaço integrador e simbólico, como um espaço de trocas e coordenação, ou como um núcleo lúdico, de acordo com Castells (2000) é assim como a cidade, um produto. Dessa forma exprime as forças sociais em ação e a estrutura de sua dinâmica interna.

${ }^{5}$ [...] Um complexo de estruturas e processos materiais, de inovações técnicas que tornam possível a modernidade. A consolidação do mundo moderno se dá com a generalização da mercadoria, com a intensificação das trocas, que tornou homens mais abertos ao novo. É o processo de consolidação do capitalismo que se coloca como a base da modernidade. Esta seria também um estado de espírito (BERMAN, 1986, p.82). 
SILVA, J.B. \& GOLÇALVES, T.E. Urbanização e produção da cidade: ...

1980, o segundo shopping em Fortaleza, no bairro Edson Queiroz, inaugurado em 1982, Shopping Iguatemi, do grupo Jereissati, mais uma vez converge para a zona leste, sendo essa composta, principalmente por bairros de classe média alta.

A implantação do shopping center Iguatemi (1982) nas proximidades do bairro da Água Fria, proporcionando amplo e diversificado atendimento de comércio e lazer (cinemas, parques, restaurantes, etc.) puxou para si grande parte dos consumidores, especialmente, os de classes média e alta, descaracterizando ainda mais o centro do comércio tradicional de Fortaleza (SOUZA, 2006, p.158).

A tendência dessa nova característica comercial de Fortaleza teve como consequências o aumento no número de shopping centers, que vêm capturando do Centro da cidade suas principais atribuições. Como nos coloca Silva (2008) um novo centro se configura na cidade, e nessa reconfiguração, tem peso a globalização. $\mathrm{O}$ ponto mais importante da cidade não é mais o porto, é o aeroporto; não é mais o comércio do Centro tradicional, é o shopping, não é mais a escola de segundo grau, é a universidade.

As sucessões de tempo muito rápidas possibilitam o surgimento e desaparecimento de novos mercados. Então, neste movimento de expansão de mercados, com a ação rápida de empreendimentos, aparecem os shopping centers, como resultado de produção da cidade e bem como atua na produção e inovação da cidade.

Essa forma de atividade comercial centralizada (shopping) congregando em um mesmo ponto espacial lazer, consumo e grande número de serviços, obteve poder de atração de parcela significativa da população urbana. De acordo com Souza (2006), o Centro de Fortaleza, que antes detinha as funções comercial e residencial, passa a ter hoje, nessa nova lógica capitalista, uma função comercial desestabilizada pelo aumento substancial dos shoppings centers. 
SILVA, J.B. \& GOLÇALVES, T.E. Urbanização e produção da cidade: ...

O abandono do Centro pela camada de maior poder aquisitivo vem acompanhada da omissão do Poder público em relação a ele. Observar-se que a área central de Fortaleza se tornou o "centro da periferia", ou seja, destinado a abastecer os perímetros, principalmente os conjuntos habitacionais e bairros totalmente desprovidos de regular infra-estrutura (SILVA, 1992).

Contrapondo a essa dinâmica comercial do Centro tradicional, evidenciam-se novas características de comércio e serviços com a instalação dos shopping centers, sendo que é perceptível uma dinâmica comercial particular, até antes não vivenciada. Com isso, faz-se necessário apreender esses empreendimentos como elemento importante na produção urbana de Fortaleza.

As atividades econômicas ligadas ao comércio sempre foram um elemento impulsionador de desenvolvimento urbano. Nesse contexto, dada a importância dos shopping centers como empreendimentos do setor terciário que oferecem no mesmo espaço; comércio, serviços e lazer têm atraído um grande número de frequentadores tanto em Fortaleza como nas grandes cidades brasileiras; posicionando, desta maneira, o Brasil em $10^{\circ}$ lugar no ranking mundial em números de shoppings, segundo a Associação Brasileira de Shopping Centers (ABRASCE).

Nesse contexto, na capital cearense, percebeu-se um acréscimo no numero de shoppings, após a instalação do Center Um, inúmeros shoppings surgem na cidade, com características variadas, de acordo com o público a que se destina, uns com maior requinte, luxo e produtos ditos de melhor qualidade, que atendem principalmente às classes mais abastadas, enquanto outros menos sofisticados que, por sua vez, atendem a população menos dotada financeiramente.

Destacam-se os shoppings principalmente nos bairros da Aldeota (zona leste): Avenida Shopping, Shopping Pátio Dom Luís, Shopping Aldeota, Shopping Del Paseo. Nesta área ocorre um grande fluxo de pessoas, mercadorias, informações, forma assim, uma das áreas mais movimentada da cidade. 
SILVA, J.B. \& GOLÇALVES, T.E. Urbanização e produção da cidade: ...

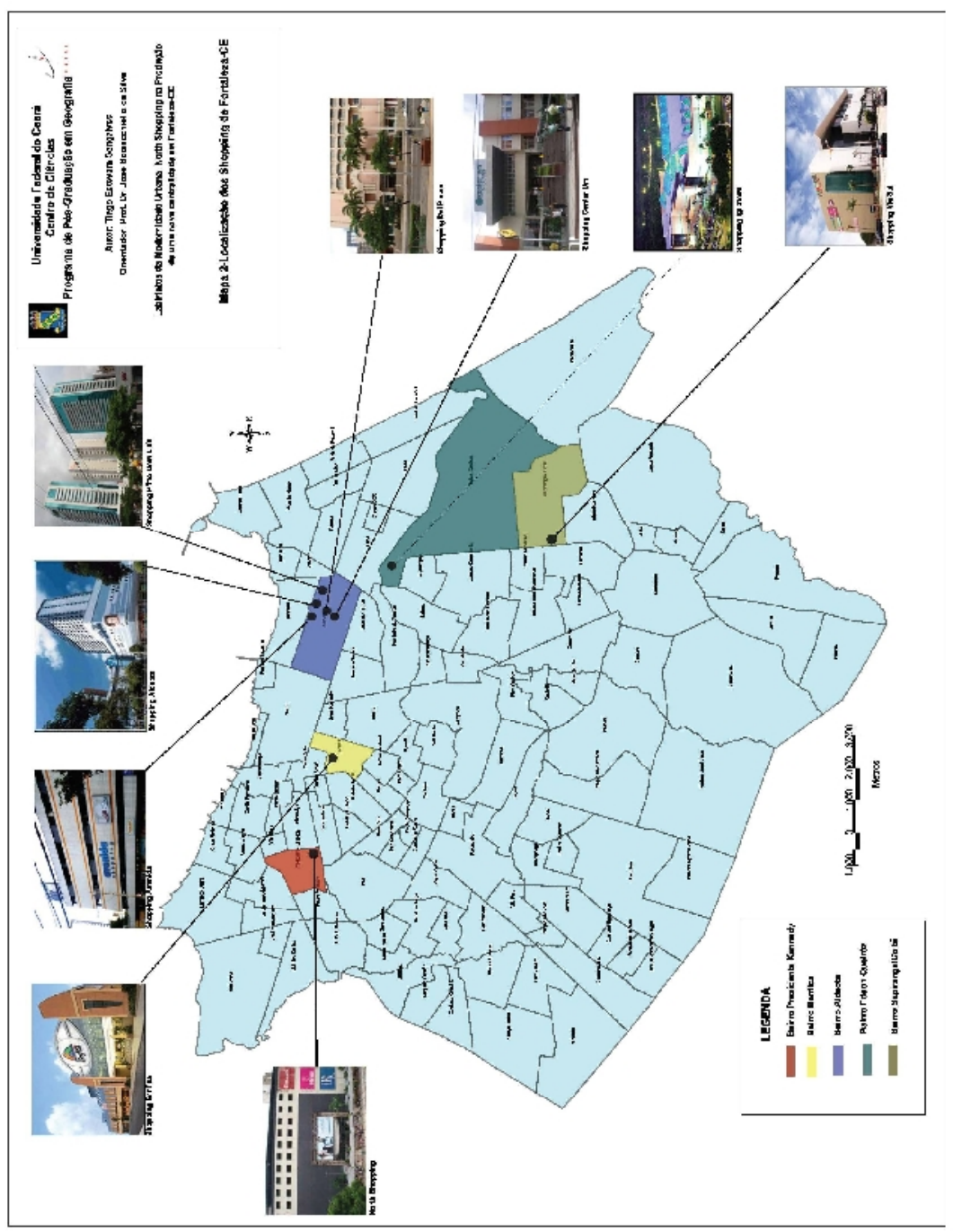


SILVA, J.B. \& GOLÇALVES, T.E. Urbanização e produção da cidade: ...

No bairro Edson Queiroz, como citado anteriormente, há como destaque o Shopping Iguatemi (1982) um dos shoppings mais importantes, atende as classes de maior poder aquisitivo. Em outra zona da cidade tem-se um importante shopping - Shopping Benfica, no bairro do mesmo nome. Este se desenvolveu em torno da Reitoria e Centro de Humanidades da Universidade Federal do Ceará - UFC.

A cidade cresce e o processo de expansão dos shopping centers atinge novos bairros. Na zona oeste, em 1991, foi inaugurado o North Shopping, na Avenida Bezerra de Menezes. Esse shopping se destaca, pois se instalou na zona oeste da cidade onde há predominância de classes de menor poder aquisitivo.

Com o surgimento de múltiplos elementos urbanísticos, dentre esses destacam-se os equipamentos de grande porte - os shopping centers. Vargas (2001) discute sobre o papel das atividades terciárias, especialmente os shopping centers, pois os considera empreendimentos de grande capital que podem produzir aglomeração e em consequência induzir o surgimento de centralidade ao promoverem concentração e fluxos, desse modo, contribuem no movimento da estrutura.

Um elemento ainda a destacar é que nesse aglomerado metropolitano e paisagem urbana revela que nas principais cidades multiplicam-se os centros comerciais (...) Junto aos eixos de maior circulação (...), centros comerciais, ligados ao grande capital comercial são construídos com seus hipermercados e shoppings centers (LENCIONI, 2003, p. 39).

As estratégias do grande capital comercial ocorrem numa relação espaço-tempo. O tempo na modernidade tem duração cada vez mais curto, é mais acelerado, implicando novas e rápidas determinações no uso do espaço urbano, desse modo, na cidade de Fortaleza, percebem-se os interesses do capital num contexto contraditório entre valorização e desvalorização, ou seja, uma desigual valorização do espaço. 
SILVA, J.B. \& GOLÇALVES, T.E. Urbanização e produção da cidade: ...

Os agentes urbanos escolhem áreas para a sua ação, parcelas da cidade que tinham atuação podem ter um acréscimo de investimentos ou aquelas que não tinham investimentos entram no cenário de interesses, assim como, algumas podem sair do cenário de investimentos.

Na cidade de Fortaleza percebem-se nitidamente modelações no seu tecido urbano, em razão da dinâmica vivenciada na urbe com uma nova relação espaço-temporal, incentivadas pelos shoppings centers, desse modo, averiguou-se novas dimensões de espraiamento da metrópole. Mediante a produção de novas centralidades, surgindo como nós articuladores de fluxos e lugares de acumulação.

Ao tentar compreender os shopping centers em Fortaleza ressalta-se sua relação intrínseca com as novas centralidades, a presença de shopping centers na malha urbana incentivaram transformações urbanas ao serem incorporados as novas áreas da cidade. Daí, um exemplo do enorme poder estruturador intraurbano das áreas comerciais e de serviços (VILLAÇA, 1998).

De um modo geral, em todo o mundo a área central das cidades se caracteriza por uma concentração mais intensa das atividades de comércio e serviços varejistas, cujo raio de atendimento é a própria cidade, embora, por vezes, esta influência comercial extrapole seus limites políticos administrativos. Entretanto, a ocorrência de cidade monocêntricas, predominantes de forma quase absoluta até meados do século $\mathrm{XX}$, hoje, restringese a regiões menos desenvolvidas ou de baixa densidade urbana.

\section{Apontamentos finais}

As condições propícias para a concretização do processo de descentralização e surgimento de novas centralidades em Fortaleza, passaram a ser percebidas a partir da década de 1970, sendo fatores importantes, o desenvolvimento suficiente de mercado consumidor, uma elite econômica e política, infra-estrutura instalada em diferentes parcelas da cidade, foram essenciais para a expansão dos 
SILVA, J.B. \& GOLÇALVES, T.E. Urbanização e produção da cidade: ...

estabelecimentos comerciais - shopping centers em novas áreas da cidade.

O shopping é lugar de encontro das novas práticas de sociabilidade urbana, transformam assim, o modo de viver urbano. Esses espaços comerciais multiplicaram-se nas últimas décadas. Cresce o número de shoppings e mais ainda o número de frequentadores. Destaca-se o fato desses equipamentos serem espaços multifacetados de uma complexidade de atributos ligados ao setor terciário tão complexo que podem possuir alguns aspectos equivalentes a uma "cidade comercial", ou seja, uma verdadeira cidade intramuros, mantendo uma áspera conversão com o urbano concreto.

Os shoppings expressam-se na dinâmica da estruturação urbana, produzindo fluxos e, conseqüentemente, articulação e concentração de certas áreas da cidade. Concorda-se com Sposito (1994) quando exprime que estes grandes equipamentos terciários (shoppings) produzem novas centralidades e procuram vazios urbanos intra ou interurbanos. Pensados de forma minuciosa e arranjado nos detalhes para o consumo, tornam-se um dos principais espaços para esse fim nas importantes cidades brasileiras.

Com a implantação e consolidação dos shopping centers em Fortaleza. Esses espaços modernos de consumo influenciam o crescimento da cidade, incentiva uma (re)organização socioespacial e favorece a formação de novos centros comerciais no seu entorno, ou seja, provoca novos arranjos da estruturação do espaço urbano, dinamizando os bairros de sua instalação e das proximidades.

Barbosa (2002) enfatiza que tem ocorrido uma redefinição dos antigos núcleos da cidade que tem perdidos seu papel de centro político, econômico, cultural e social. Enquanto os shoppings têm aparecido agora como centro, com todo o seu poder aglutinador de pessoas e de sedução mercadológica. Desse modo, a expansão dos shopping centers, está associada, entre outros fatores, ao processo 
SILVA, J.B. \& GOLÇALVES, T.E. Urbanização e produção da cidade: ...

de descentralização que ao mesmo que se descentraliza não deixa de existir uma centralização das atividades comerciais.

\section{Referências bibliográficas}

BARBOSA, Luciano César Bezerra. Análise das condições de conforto térmico em um shopping center em Natal/RN com base na avaliação pós-ocupação. Natal/UFRN, dissertação de Mestrado, 2002.

BAUDRILLARD, Jean. A sociedade de Consumo. Lisboa: Edições 70, 1995.

BAUMAN, Zygmunt. Tempos Líquidos. Rio de Janeiro: Jorge Zahar., 2007.

CALDEIRA, Teresa Pires do Rio. Cidade de Muros: Crime, segregação e cidadania em São Paulo. São Paulo: Edusp, 2000.

CARLOS, Ana Fani Alessandri. A cidade. São Paulo: Contexto, 1997.

CARLOS, Ana Fani Alessandri. Espaço-Tempo na Metrópole. São Paulo: Contexto, 2001.

CARLOS, Ana Fani Alessandri. Espaço urbano. Novos escritos sobre a cidade. São Paulo: Contexto, 2004.

CARLOS, Ana Fani. O lugar no/do mundo. São Paulo: Hucitec, 1996.

CARVALHO, Madalena Grimaldi de. A difusão e a integração dos Shoppings Centers na cidade: As particularidades do Rio de Janeiro. Rio de Janeiro/ UFRJ, tese de doutorado, 2005.

CORRÊA, Roberto Lobato. O Espaço Urbano. São Paulo: Ática, 2001.

CORRÊA, Roberto Lobato. Região e organização espacial. São Paulo: Ática, 1988. 
SILVA, J.B. \& GOLÇALVES, T.E. Urbanização e produção da cidade: ...

CORRÊA, Roberto Lobato. A Rede Urbana. São Paulo: Ática, 1986.

CORRÊA, Roberto Lobato. Espaço: um conceito chave de Geografia. In CORRÊA, Roberto Lobato. Geografia: Conceitos e Temas. Rio de Janeiro: Bertrand Brasil, 1995.

CORREAA, Roberto Lobato. Repensando a teoria das localidades centrais. In: MOREIRA, Ruy. Geografia: teoria e crítica: o saber posto em questão. Petrópolis: Vozes, 1982.

CASTELLS, Manuel. A questão urbana. Rio de Janeiro: Paz e Terra, 2000.

COSTA, Maria Clélia Lustosa da. Fortaleza: expansão urbana e organização do espaço. In. SILVA, José Borzacchiello da; CAVALCANTE, Tércia Correia; DANTAS, Eustógio Wanderley Correia (org.). Ceará: um novo olhar geográfico. Fortaleza: Edições Demócrito Rocha, 2005.

FRÚGOLI JÚNIOR, Heitor. Os Shoppings de São Paulo e a Trama do Urbano. Um olhar Antropológico. In PINTAUDI, Silvana Maria e FRÚGOLI JÚNIOR (orgs) Shoppings centers: espaço, cultura e modernidade nas cidades brasileiras. São Paulo: Editora da Universidade Federal Paulista, 1992.

GIDDENS, Anthony. As conseqüencias da Modernidade. São Paulo: UNESP, 1991.

GOMES, Paulo César da Costa. A condição urbana. Rio de Janeiro: Bertand Brasil, 2002.

GOTTDIENER, Mark. A produção social do espaço urbano. São Paulo, EDUSP, 1993.

LEFEBVRE, Henri. A vida cotidiana no mundo moderno. São Paulo; Ática, 1991.

LEFEBVRE, Henri. $O$ Direito à Cidade. São Paulo: Editora Moraes, 1993. 
SILVA, J.B. \& GOLÇALVES, T.E. Urbanização e produção da cidade: ...

LEFEBVRE, Henri. A revolução Urbana. Belo Horizonte: Editora UFMG, 2002.

LENCIONI, Sandra. Uma nova determinação do urbano: o desenvolvimento do processo de metropolização do espaço. In CARLOS, Ana Fani Alessandri. (org.). LEMOS, Amália Inês Geraiges. (org.). Dilemas Urbanos - Novas Abordagens sobre a cidade. São Paulo: Contexto, 2003.

LOPES, Francisco Clébio Rodrigues. A centralidade $d a$ Parangaba como produto da fragmentação de Fortaleza (CE). Fortaleza, Universidade Federal do Ceará, dissertação, 2006.

PADILHA, Valquíria. Shopping Center: a catedral das mercadorias. São Paulo: Boitempo Editorial, 2006.

PINTAUDI, Silvana Maria; FRÚGOLI JÚNIOR, Heitor (orgs). Shopping Centers: Espaço, Cultura e Modernidade nas cidades brasileiras. São Paulo: Editora Estadual Paulista, 1992.

REIS, Nestor Goulart. Notas sobre a urbanização dispersa e novas formas do tecido urbano. São Paulo: Via das Artes, 2006.

RYBCZYNSKI, Witold. A vida nas cidades: Expectativas urbanas no Novo Mundo. Tradução: Beatriz Horta. Rio de Janeiro: Record, 1996.

SALGUEIRO, Teresa Barata Cidade pós-moderna: espaço fragmentado. Revista Território, Rio de Janeiro, ano III, n. 4, 1998.

SANTOS, Milton, SOUZA, Maria Adélia, SILVEIRA, Maria Laura (org). Território, globalização e fragmentação. São Paulo: Hucitec e ANPUR, 1994.

SANTOS, Milton. A natureza do espaço - técnica e tempo, razão e emoção. São Paulo: Hucitec, 1996.

SANTOS, Milton. A urbanização brasileira. São Paulo, Hucitec, 1993. 
SILVA, J.B. \& GOLÇALVES, T.E. Urbanização e produção da cidade: ...

SILVA, José Borzacchiello da..Quando os incomodados não se retiram: uma análise dos movimentos sociais em Fortaleza. Fortaleza: Multigraf, 1992.

SILVA, José Borzacchiello da. Reinventando Fortaleza: o saber geográfico e outros saberes na interpretação da cidade. In Carlos, Ana Fani Alessandri. (org.). Os caminhos da reflexão sobre a cidade e o urbano. São Paulo: Edusp, 1994.

SILVA, José Borzacchiello da. Novos Desafios para as Grandes Cidades Brasileiras. Revista CCHLA/UFRN Natal v. 10 n.1/2 $\mathrm{jan} / \mathrm{dez} 96$.

SOUZA, Maria Salete de Souza. Fortaleza: uma análise da estrutura urbana. In: Encontro Nacional de Geógrafos, 3., 1978, Fortaleza. Anais, Fortaleza: UFC, 1978.

SOUZA, Maria Salete de. Ceará: bases de fixação do povoamento e o crescimento das cidades. In: SILVA, José Borzacchiello da (Org.); CAVALCANTE, Tércia Correia (org.) DANTAS, Eustógio Wanderley Correia (org.). Ceará: um novo olhar geográfico. Fortaleza: Edições Demócrito Rocha, 2005.

SOUZA, Maria Salete de Souza. Segregação socioespacial em Fortaleza. In: SILVA, José Borzacchiello da (Org.); DANTAS, Eustógio Wanderley Correia (org.). . ZANELLA, Maria Elisa (org); MEIRELES, Antônio Jeovah de Andrade (org.). Litoral e Sertão. Natureza e sociedade no Nordeste brasileiro. Fortaleza: Expressão Gráfica, 2006.

SPOSITO, M. Encarnação B. A gestão do território e as diferentes escalas da centralidade urbana. Revista Território. Rio de Janeiro: LAGET/UFRJ, n. 4, 1998.

SPOSITO, M. Encarnação B. O centro e as expressões de centralidade urbana. Revista Geografia, São Paulo, n. 10, 1991. 
SILVA, J.B. \& GOLÇALVES, T.E. Urbanização e produção da cidade: ...

SPOSITO, M. Encarnação B. O chão em pedaços: Urbanização, economia e cidade de São Paulo. Presidente Prudente: [s.n], 2004a. (Tese Livre Docência).

SPOSITO, Maria Encarnação Beltrão. Capitalismo e urbanização. $4^{\circ}$ ed. São Paulo: Contexto, 1991.

SPOSITO, Maria Encarnação Beltrão. A cidade e seus territórios. In: Anais $5^{\circ}$ Congresso Brasileiro de Geógrafos. Curitiba: AGB, 1994.

SPOSITO, Maria Encarnação Beltrão (org.). Novas formas comerciais e a redefinição da centralidade intra-urbana. Urbanização e cidades: Perspectivas geográficas. Presidente Prudente: UNESP, GASPERR, 2001.

VAINER, Carlos. Pátria, empresa e mercadoria. In: Arantes, Otília; MARICATO, Ermínia; VAINER, Carlos (orgs). A cidade do pensamento único: Desmanchando consensos. Petrópolis: Editora Vozes, 2000.

VARGAS, Heliana Comin. Espaço terciário: o lugar, a arquitetura e a imagem do comércio. São Paulo: SENAC, 2001.

VILLAÇA, Flávio. Espaço intra-urbano no Brasil. Rio de Janeiro: Stúdio Nobel; 1998.

Recebido em setembro de 2011 Aceito em novembro de 2011 